\title{
Changes in Direct Medical Cost and Medications for Managing Diabetes in Beijing, China, 2016 to 2018: Electronic Insurance Data Analysis
}

\author{
Lixin Guo ${ }^{1^{*}}$ \\ Jie Zheng ${ }^{2 *}$ \\ Qi $\operatorname{Pan}^{1^{*}}$ \\ Qun Zhang \\ Yan Zhou ${ }^{1}$ \\ Weibao Wang ${ }^{1}$ \\ Lina Zhang ${ }^{1}$ \\ Solomon Tesfaye $e^{4}$ \\ Jie Zhang ${ }^{1}$
}

'Department of Endocrinology, Beijing Hospital, National Center of Gerontology, Institute of Geriatric Medicine, Chinese Academy of Medical Sciences, Beijing, PR China

${ }^{2}$ Beijing Municipal Medical Insurance Bureau, Beijing, PR China

${ }^{3}$ Department of Medical Insurance, Beijing Hospital, National Center of Gerontology, Institute of Geriatric Medicine, Chinese Academy of Medical Sciences, Beijing, PR China

${ }^{4}$ Diabetes Research Unit, Sheffield Teaching Hospitals, Sheffield, United Kingdom

*These authors contributed equally as cofirst authors.

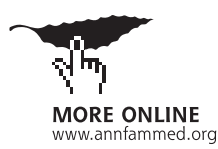

Conflicts of interest: authors report none.

\section{CORRESPONDING AUTHOR}

Lixin Guo

Department of Endocrinology, Beijing Hospital, National Center of Gerontology Institute of Geriatric Medicine, Chinese Academy of Medical Sciences 100730, Beijing, PR China glxwork2016@163.com

\begin{abstract}
PURPOSE Although the cost and complexity of managing diabetes is increasing around the world, placing greater burden on patients and their families, the cost of drug regimens prescribed to Chinese patients has not been evaluated. This study was conducted to evaluate the temporal changes in the costs and drugs used for people with diabetes.
\end{abstract}

METHODS Patients enrolled in Beijing Medical Insurance with outpatient medical records from 2016 through 2018 were included in this study. The outcomes of interest were: (1) the number of outpatient medications, (2) the number of comorbidities diagnosed, (3) the estimated annual cost of the outpatient drug regimen, (4) the drug therapy strategies used for diabetic patients, and (5) the most commonly prescribed classes of drugs.

RESULTS Over the 3-year period, there was a significant decrease $19.0 \%$, $P<.001)$ in the average number of diabetes medications used. Both antiglycemic and non-antiglycemic drug use decreased by $3.6 \%$ and $12.9 \%$, respectively. Similarly, for estimated annual costs of medication, an $18.4 \%(P<.05)$ decrease was observed, with a gradual decreased from $¥ 6,868(\$ 1,059)$ in 2016 to $¥ 5,605$ (\$865) in 2018 .

CONCLUSION This is the first large-scale cost analysis of the medical management of diabetes since the implementation of medical insurance in China. Despite the increasing availability of newer, more expensive diabetes drugs, there was a significant reduction in the number of diabetes medications used, that may be due to a more rational approach to optimizing metabolic targets.

Ann Fam Med 2021;19:332-341. https://doi.org/10.1370/afm.2686.

\section{INTRODUCTION}

$\mathrm{D}$ iabetes is one of the 4 major noncommunicable diseases ${ }^{1}$ and is a cause of premature death and disability. International Diabetes Federation data show that 415 million individuals worldwide were projected to have diabetes in 2015. This projection has now been exceeded, as approximately 642 million people are expected to develop diabetes by 2040, with more than 55\% of these people residing in Asia. ${ }^{2}$ Diabetes increases the burden on global health care systems either directly due to medical costs or indirectly due to loss of productivity and early mortality. Health care costs for people with diabetes is 2 to 3 times higher than for those without. Costs, in China, ranged from $\$ 673$ billion to $\$ 1,197$ billion in 2015 , and are expected to exceed $\$ 802$ billion to $\$ 1,452$ billion by $2040 .{ }^{3}$ Unfortunately for many people in the developing world, these costs put excessive financial burden on patients with diabetes and their families.

The prevalence of diabetes in China has increased 10 -fold in the past decade and with 114 million people affected, China has the largest population with diabetes in the world. ${ }^{2,4,5}$ A full range of diabetes drugs, antiglycemic and non-antiglycemic, are available in China and in most 
countries across the world, yet the proportion of the population with diabetes receiving medical treatment is $41.8 \%$ in urban areas and lower $(27.6 \%)$ in rural areas. ${ }^{4}$ Moreover, some studies have shown that the health care expenditures on the diabetic population in China have risen substantially. According to the 2008 National Health Service Survey, the estimated direct medical cost of diabetes was approximately $\$ 8.65$ billion. ${ }^{6}$ In 2009-2010, Yang et $\mathrm{al}^{7}$ interviewed 1,482 adults with diabetes at 12 different locations in China to evaluate the medical care and costs for diabetes. They found that annual cost for medications from all sources reached $¥ 1,573$ (\$243) per person. The average hospitalization cost of urban patients with diabetes was $¥ 16,204(\$ 2,499)$, while that of rural patients was $¥ 3,643$ (\$562). Studies have estimated and compared the cost-effectiveness of some commonly used drug combination therapies for type 2 diabetes according to clinical guidelines. ${ }^{8-10}$ Indirect costs of diabetes-related cardiovascular diseases or secondary infections, however, have not been measured in most studies, ${ }^{11}$ leading to gross underestimation of diabetesrelated health care costs.

Similar to other countries, such as the United Kingdom, where diabetes and its complications consume around $10 \%$ of the total national health costs, ${ }^{12}$ China's expenditure was $13 \%$ ( $\$ 25$ billion) of its total health care costs in 2008. ${ }^{3}$ In 2009, China initiated a series of new health care reforms and committed to spending an additional $\$ 125$ billion in the next 3 years, with the goal of providing affordable and equitable basic health care for all by $2020 .{ }^{13}$ The outpatient costs in China varied across geographic locations and age groups, with the medical management of the diabetic population becoming increasingly complex due to an increase in comorbidities. Recent studies indicated that the rate of glycemic control in patients with diabetes is low despite polypharmacy. ${ }^{14,15}$

Since the implementation of China's health insurance policy in 2018, the overall direct cost of diabetes has not been documented. With the assumption that Beijing is a representative city of China, this study aimed to analyze the changes in treatment costs and trends in medications prescribed in Beijing's Medicare cohort with diabetes from 2016 through 2018.

\section{METHODS}

\section{Study Design and Ethical Approval}

An observational, retrospective, multi-center study was conducted to estimate the changes in direct costs of treatment for patients with diabetes in China over 3 years. The study was approved by the ethics committee of Beijing Hospital.

\section{Study Population and Data Collection}

The study population included patients enrolled in Beijing's medical insurance with outpatient drug treatment records from 2016 through 2018. The cohorts included 897,385 patients in 2016; 959,509 patients in 2017; and 996,142 patients in 2018. Patients were excluded if they had did not have (1) a diagnosis of diabetes (no diabetes entry in primary or secondary diagnosis), or (2) a continuous prescription record (gaps of 2 months). In the current medical insurance reimbursement system, it is impossible to prescribe medication for more than 30 days. Therefore, from a study sampling point of view, patients who take medication according to the doctor's advice need to take the medication again within 2 months. A more detailed description is provided in Supplemental Table 1, available at https://www.AnnFamMed.org/content/19/4/332/ suppl/DC1/. The Beijing medical insurance database contains demographic and clinical data including date of birth, sex, race, diabetes history, non-diabetes medical history, medications, and medical costs. The data extracted from the medical records consisted of all medical prescriptions and medical costs. Each prescription in the medical insurance database has a unique serial number, and all the medical information was merged according to the serial number.

\section{Outcomes of Interest}

The main purpose of this study was to evaluate the complexity and cost of long-term treatment and the variation in type of treatment and treatment costs of diabetes in Beijing, China. The end points of analysis of this study included: (1) the number of outpatient medications, (2) the number of additional diseases diagnosed (comorbidities), (3) the estimated annual cost of the outpatient drug regimen, (4) the drug therapy strategies used, and (5) the most commonly prescribed drug class. All the analyses were performed for antiglycemic and non-antiglycemic regimens. Any short-term drugs used (eg, antibiotics) were excluded.

\section{Antiglycemic Treatments and Definitions Used}

The change in antiglycemic drug use was assessed by drug class for each study year. Drug classes included in medical insurance were $\alpha$-glucosidase inhibitors, metformin, insulin, sulfonylureas, dipeptidyl peptidase- 4 inhibitors, prandial glucose regulators (glinides) and thiazolidinediones. A patient was considered receiving any antiglycemic drug if they had been treated with at least 1 antiglycemic drug prescription in each study year. Monotherapy means patients received only 1 recorded antiglycemic drug prescription in the past 1 year. Oral combination therapy means patients received 2 or more oral antiglycemic drug 
prescriptions in different classes in the past 1 year. Oral drug and insulin combination therapy indicates that patients received at least 1 oral antiglycemic drug prescription and at least 1 insulin prescription in the past 1 -year period.

All drugs were classified according to the American Society of Health-System Pharmacists Drug Information Classification System. The summary of medications from all included patients of the study cohort was reviewed by 2 statisticians and 2 clinicians.

\section{Statistical Analysis}

The percentage distributions of the number of medications, diagnosed diseases, and estimated annual costs were compared by Wilcoxon rank sum test. Chi-square test $\left(\chi^{2}\right)$ and Fisher's exact test were used as tests of significance for categorical variables. In order to assess the number of drugs, a negative binomial model and log link function were used as the distributions of the outcome variables were not normal. This approach is appropriate for count data characterized by overdispersion. For the cost models, the estimated cost was log-transformed. In order to correct for retransformation bias due to heteroscedasticity, a smearing estimator was used, which provided estimates of the adjusted arithmetic means of annual costs on a linear scale for greater interpretability. In order to adjust the number of medications and annual cost by demographic, medical history, and diabetic complication, the above mentioned multivariable regression models included covariables such as age, sex, hypertension, coronary heart disease, dyslipidemia, stroke, chronic lung disease, osteoporosis, diabetic peripheral neuropathy, diabetic nephropathy, diabetic neuropathy, comorbidities complications, and a variable for the year of sampling (2016, 2017, and 2018) to assess the changes over time. The analysis was performed with SAS software, version 9.4 (SAS Institute, Inc), with an a priori $\alpha$ level of 0.05 (2-sided) to determine statistical significance.

\section{RESULTS}

\section{Demographics the Study Population}

Analysis of data from 996,142 patients, collected in 2018, revealed the following. The majority of patients $(51.2 \%)$ were aged 45 to 64 years, with $2.9 \%$ of patients aged $>85$ years. Further, $52.4 \%$ of the recruited patients were males. The most frequent comorbidities observed were hypertension $(61.3 \%)$, coronary heart disease $(48.8 \%)$, dyslipidemia $(47.4 \%)$, stroke (19.7\%), chronic lung disease (17.6\%), and osteoporosis (13.3\%) Data from 2016 and 2017 are included in Supplemental Table 2 (available at https:// www.AnnFamMed.org/content/19/4/332/supp1/DC1/).

\section{Changes in Antiglycemic Medication, Disease, and Costs}

On an average, 3.64 medications (1.57 antiglycemic drugs and 2.07 non-antiglycemic drugs) were used to treat 4.74 comorbidities ( 1.25 as consequence of hyperglycemia and 3.49 not related to hyperglycemia). The mean annual cost of medication was $¥ 6,033$ (\$931) that included $¥ 3,387$ ( $\$ 522$ ) for antiglycemic drugs and $¥ 2,646$ (\$408) for non-antiglycemic drugs. Over 3 years, there was a gradual, statistically significant $(P$ $<.001)$, decrease in the average number of medications by $9.0 \%$. The mean number of both antiglycemic and non-antiglycemic drugs used decreased by $3.6 \%$ and $12.9 \%$, respectively. Similarly, the estimated annual cost of medications decreased by $18.4 \%$ (from $¥ 6,868$ $[\$ 1,059]$ in 2016 to $¥ 5,605[\$ 863]$ in $2018, P<.05)$. The use and cost of medications by year are presented in Table 1. Results from the same cohort of participants who had information documented consecutively for 3 years showed a similar trend compared with the former analysis (Supplemental Table 3, available at https:// www.AnnFamMed.org/content/19/4/332/suppl/DC1/).

\section{Cost of Medication, Demographic Factors, and Disease History}

In the group of patients aged 15 to 44 years, the cost of treatment was $¥ 7,605$ ( $\$ 1,173$ ) for a mean of 3.71 drugs, which was the highest among all age groups. The cost of treatment was lower in female patients and in patients without comorbidities. Patients without comorbidities incurred a total treatment cost of $¥ 2,358$ (\$364). Cost increased to $¥ 28,066(\$ 4,329)$ for patients with a maximum of 6 comorbidities. Similarly, patients without documented complications incurred a total treatment cost of $¥ 6,576(\$ 1,014)$, whereas patients with a maximum of 3 complications incurred a cost of $¥ 11,304(\$ 1,744)$ and had a concurrent increase in the number of drugs. We listed the prices for some of the commonly used drugs in Supplemental Table 4, available at https://www.AnnFamMed.org/content/19/4/332/ suppl/DC1/. The $P$ values of all regression coefficients were less than 0.001 , meaning that all the factors above had a statistically significant impact on the cost of medications (Table 2).

\section{Changes in Diabetes Treatment Regimens}

While $86.3 \%$ of patients received a minimum of 1 antiglycemic drug in 2016, only $84.7 \%$ received treatment in 2018. The $\alpha$-glucosidase inhibitors were the most commonly used drugs, both as monotherapy (12.4\% in 2016, and $13.1 \%$ in 2017 and 2018) and in combination with metformin $(7.8 \%$ in $2016,8.0 \%$ in 2017, and $8.3 \%$ in 2018) followed by metformin alone, premixed insulin, sulfonylureas, dipeptidyl peptidse- 4 
Table 1. Changes in Medications, Comorbidities, and Costs, 2016-2018

\begin{tabular}{|c|c|c|c|c|c|c|}
\hline \multirow[b]{2}{*}{ Outcome Measured } & \multirow{2}{*}{$\begin{array}{c}\text { Mean for } \\
2016-2018\end{array}$} & \multicolumn{3}{|c|}{ Mean for Each Year } & \multirow{2}{*}{$\begin{array}{l}\text { Change from } \\
2016 \text { to } 2017 \\
\text { No. (\%) }\end{array}$} & \multirow{2}{*}{$\begin{array}{l}\text { Change from } \\
2016 \text { to } 2018 \\
\text { No. (\%) }\end{array}$} \\
\hline & & 2016 & 2017 & 2018 & & \\
\hline Number of medications & 3.64 & 3.83 & 3.63 & 3.48 & $-0.20(-5.2)$ & $-0.34(-9.0)$ \\
\hline Antiglycemic drugs & 1.57 & 1.61 & 1.56 & 1.55 & $-0.05(-3.35)$ & $-0.06(-3.6)$ \\
\hline Non-antiglycemic drugs & 2.07 & 2.22 & 2.07 & 1.93 & $-0.15(-7.0)$ & $-0.29(-12.9)$ \\
\hline Number of comorbidities & 4.74 & 4.74 & 4.80 & 4.69 & $0.06(1.2)$ & $-0.05(-1.1)$ \\
\hline Glycemic diseases & 1.25 & 1.26 & 1.25 & 1.25 & $-0.01(-0.6)$ & $-0.01(-0.8)$ \\
\hline Non-glycemic diseases & 3.49 & 3.49 & 3.55 & 3.45 & $0.06(1.8)$ & $-0.04(-1.2)$ \\
\hline Total annual drug cost, $¥$ & 6,033 & 6,868 & 5,701 & 5,605 & $-1,167(-17.0)$ & $-1,263(-18.4)$ \\
\hline Antiglycemic drugs & 3,387 & 3,729 & 3,221 & 3,240 & $-508(-13.6)$ & $-489(-13.1)$ \\
\hline Non-antiglycemic drugs & 2,646 & 3,139 & 2,480 & 2,365 & $-659(-21.0)$ & $-774(-24.7)$ \\
\hline Total annual cost/drug, $¥$ & 1,591 & 1,718 & 1,511 & 1,553 & $-207(-12.1)$ & $-165(-9.6)$ \\
\hline Cost/antiglycemic drug/) & 2,046 & 2,192 & 1,968 & 1,986 & $-224(-10.2)$ & $-207(-9.4)$ \\
\hline Cost/non-antiglycemic drug & 1,191 & 1,314 & 1,117 & 1,148 & $-198(-15.0)$ & $-166(-12.6)$ \\
\hline
\end{tabular}

inhibitors, glinides, and thiazolidinediones (Supplemental Table 5, available at https://www.AnnFamMed. org/content/19/4/332/suppl/DC1/). Premixed insulin was the most commonly prescribed drug for combination treatment and accounted for $24.1 \%, 22.5 \%$, and $20.7 \%$ of medications in 2016, 2017, and 2018, respectively. Among the different types of insulin, the use of fast-acting insulin and long-acting insulin showed a statistically significant increase in use during the study period, whereas the other types of insulin showed a significant decrease $(P<.001)$, as shown in Table 3.

\section{Changes in the Prescription of Antiglycemic and Non-Antiglycemic Drugs}

Among the antiglycemic drugs, $\alpha$-glucosidase inhibitors were the most frequently prescribed drug class ( $48.2 \%$ in $2016,46.8 \%$ in 2017 , and $45.8 \%$ in 2018). Among the non-antiglycemic drugs, the most significant change was observed in the use of traditional Chinese medicines, which dropped from $23.7 \%$ in 2016 to $14.7 \%$ in 2018 . Irrespective of the drug class, the use of all diabetic medications decreased from 2016 through 2018 for both antiglycemic and non-antiglycemic drugs (Figure 1).

\section{DISCUSSION}

The global cost of diabetes is estimated to be $2 \%$ to $3 \%$ of overall health care spending in every country, and the constant increase in disease prevalence adds to the economic burden annually. ${ }^{16}$ Medical costs incurred by people with diabetes are approximately 2.3 times more than for those without diabetes. ${ }^{17}$ Our study showcases the prescription drug costs of insured patients with diabetes in Beijing. The results of our study indicate that annual medication costs had gradually decreased from 2016 to 2018 across different drug classes and for patients with different comorbidities. This finding is in contrast with a study conducted in Germany for the period of 1994 to $2004{ }_{1}^{18}$ which showed a $60 \%$ increase in direct medical costs. The decrease in medical costs observed in our study could be explained by a more rational use of medications leading to a decrease in medications used over the 3 years of our study, especially the needless use of most types of insulin.

Patients with comorbidities and complications showed an increase in the mean number of medications and associated costs and, as expected, these patients had greater total direct medical costs. This finding is consistent with those of other studies. ${ }^{19-25}$ Specifically, a study in 2012 reported that approximately $18 \%$ of the direct medical costs of patients with diabetes was attributed to treatment of complications and comorbidities. ${ }^{17}$ Diabetic complications are thought to be one of the key factors in determining both quality of life and health care costs. A previous study showed that hospitalization costs accounted for the largest portion of diabetes-associated costs. ${ }^{26}$ Patients who develop late complications might require extra inpatient hospital care and a longer hospital stay, ${ }^{27}$ resulting in greater costs. New data from the UK Prospective Diabetes Study also showed that diabetic complications are associated with substantial immediate and long-term health care costs, and that the highest average annual costs were attributable to amputation, followed by ischemic heart disease, myocardial infarction, and stroke. ${ }^{28}$ As a chronic disease, increased duration of diabetes is associated with increased risk of serious complications and increased medical costs. 
In 2013, a study that included 238,639 patients in 606 hospitals across China showed that less than one-third of patients with diabetes reached the goal of glycated hemoglobin $<7.0 \% .{ }^{29}$ Patients with diabetes were treated with either oral antiglycemic drugs alone $(66 \%)$ or oral antiglycemic drugs plus insulin $(34 \%) .{ }^{29}$ Another retrospective database study in China showed that approximately three-fourths of patients

Table 2. Number and Cost of Medications in Stratified Patient Groups

\begin{tabular}{|c|c|c|c|c|c|c|}
\hline Patient Group & Parameter & $\begin{array}{l}\text { No. of } \\
\text { Patients }\end{array}$ & Mean & SD & $\begin{array}{l}\text { Adjusted } \\
\text { Mean }\end{array}$ & $\begin{array}{l}\text { Difference Compared } \\
\text { With Reference }\end{array}$ \\
\hline \multicolumn{7}{|l|}{ Age, y } \\
\hline \multirow[t]{2}{*}{$\geq 85$} & No. of medications & 74,064 & 3.74 & 2.33 & 3.80 & Ref \\
\hline & Cost, $¥$ & 71,917 & 6,007 & 4,777 & 6,333 & Ref \\
\hline \multirow[t]{2}{*}{$15-44$} & No. of medications & 234,195 & 2.66 & 2.05 & 3.71 & -0.09 \\
\hline & Cost, $¥$ & 210,571 & 4,660 & 4164 & 7,605 & 1,272 \\
\hline \multirow[t]{2}{*}{$45-64$} & No. of medications & $1,490,660$ & 3.62 & 2.31 & 3.90 & 0.12 \\
\hline & Cost, $¥$ & $1,431,655$ & 6,041 & 4,904 & 7,155 & 822 \\
\hline \multirow[t]{2}{*}{$65-84$} & No. of medications & $1,054,117$ & 3.88 & 2.39 & 3.89 & 0.09 \\
\hline & Cost, $¥$ & $1,023,208$ & 6,307 & 4973 & 6,732 & 398 \\
\hline \multicolumn{7}{|l|}{ Sex } \\
\hline \multirow[t]{2}{*}{ Male } & No. of medications & $1,464,378$ & 3.70 & 2.34 & 3.95 & Ref \\
\hline & Cost, $¥$ & $1,415,413$ & 6,069 & 4,888 & 7,327 & Ref \\
\hline \multirow[t]{2}{*}{ Female } & No. of medications & $1,388,658$ & 3.57 & 2.34 & 3.71 & -0.24 \\
\hline & Cost, $¥$ & $1,321,938$ & 5,995 & 4895 & 6,630 & -697 \\
\hline \multicolumn{7}{|l|}{ Hypertension } \\
\hline Absent & No. of medications & $1,096,600$ & 2.10 & 1.54 & 2.90 & Ref \\
\hline Present & & $1,756,436$ & 4.60 & 2.24 & 5.04 & 2.14 \\
\hline Absent & Cost, $¥)$ & $1,003,635$ & 3,866 & 3,417 & 4,034 & Ref \\
\hline Present & & $1,733,716$ & 7,288 & 5,170 & 8,226 & 4,192 \\
\hline \multicolumn{7}{|c|}{ Coronary heart disease } \\
\hline Absent & No. of medications & $1,442,472$ & 2.62 & 1.86 & 3.36 & Ref \\
\hline Present & & $1,410,564$ & 4.68 & 2.32 & 4.36 & 1.00 \\
\hline Absent & Cost, $¥$ & $1,345,084$ & 4,413 & 3,778 & 5,330 & Ref \\
\hline Present & & $1,392,267$ & 7,599 & 5,319 & 8,045 & 2,715 \\
\hline \multicolumn{7}{|l|}{ Dyslipidemia } \\
\hline Absent & No. of medications & $1,524,133$ & 2.61 & 1.83 & 3.22 & Ref \\
\hline Present & & $1,328,903$ & 4.82 & 2.31 & 4.55 & 1.32 \\
\hline Absent & Cost, $¥$ & $1,427,259$ & 4,382 & 3,714 & 4,961 & Ref \\
\hline Present & & $1,310,092$ & 7,833 & 5,363 & 8,548 & 3,588 \\
\hline \multicolumn{7}{|l|}{ Stroke } \\
\hline Absent & No. of medications & $2,248,774$ & 3.40 & 2.26 & 3.71 & Ref \\
\hline Present & & 604,262 & 4.53 & 2.40 & 3.95 & 0.24 \\
\hline Absent & Cost, $¥$ & $2,143,127$ & 5,612 & 4,630 & 6,805 & Ref \\
\hline Present & & 594,224 & 7,554 & 5,475 & 7,455 & 650 \\
\hline \multicolumn{7}{|c|}{ Chronic lung disease } \\
\hline Absent & No. of medications & $2,324,751$ & 3.52 & 2.31 & 3.71 & Ref \\
\hline Present & & 528,285 & 4.15 & 2.40 & 3.95 & 0.24 \\
\hline Absent & Cost, $¥$ & $2,217,914$ & 5,838 & 4,791 & 6,743 & Ref \\
\hline Present & & 519,437 & 6,870 & 5,220 & 7,888 & 1,145 \\
\hline
\end{tabular}

Ref $=$ reference .

Note: Adjusted variables include age, sex, hypertension, coronary heart disease, dyslipidemia, stroke, chronic lung disease, osteoporosis, diabetic peripheral neuropathy, diabetic nephropathy, diabetic neuropathy, comorbidity, complication and a variable for the sampling time frame (2016, 2017, and 2018). Values of all regression coefficients above were significant at $P<.001$. 
Table 2. Number and Cost of Medications in Stratified Patient Groups (continued)

\begin{tabular}{|c|c|c|c|c|c|c|}
\hline Patient Group & Parameter & $\begin{array}{l}\text { No. of } \\
\text { Patients }\end{array}$ & Mean & SD & $\begin{array}{l}\text { Adjusted } \\
\text { Mean }\end{array}$ & $\begin{array}{l}\text { Difference Compared } \\
\text { With Reference }\end{array}$ \\
\hline \multicolumn{7}{|l|}{ Osteoporosis } \\
\hline Absent & No. of medications & $2,446,815$ & 3.53 & 2.31 & 3.72 & Ref \\
\hline Present & & 406,221 & 4.33 & 2.37 & 3.94 & 0.23 \\
\hline Absent & Cost, $¥$ & $2,336,977$ & 5,806 & 4,765 & 6,748 & Ref \\
\hline Present & & 400,374 & 7,362 & 5,386 & 8,117 & 1,369 \\
\hline \multicolumn{7}{|c|}{ Diabetic peripheral neuropathy } \\
\hline Absent & No. of medications & $2,477,820$ & 3.51 & 2.29 & 3.69 & Ref \\
\hline Present & & 375,216 & 4.47 & 2.48 & 3.97 & 0.28 \\
\hline Absent & Cost, $¥$ & $2,370,132$ & 5,801 & 4,755 & 6,818 & Ref \\
\hline Present & & 367,219 & 7,530 & 5,464 & 7,821 & 1,003 \\
\hline \multicolumn{7}{|c|}{ Diabetic nephropathy } \\
\hline Absent & No. of medications & $2,732,287$ & 3.60 & 2.32 & 3.68 & Ref \\
\hline Present & & 120,749 & 4.56 & 2.59 & 3.98 & 0.3 \\
\hline Absent & Cost, $¥$ & $2,619,298$ & 5,939 & 4,817 & 6,924 & Ref \\
\hline Present & & 118,053 & 8,122 & 5,951 & 8,034 & 1,110 \\
\hline \multicolumn{7}{|c|}{ Diabetic neuropathy } \\
\hline Absent & No. of medications & $2,726,009$ & 3.58 & 2.31 & 3.55 & Ref \\
\hline Present & & 127,027 & 4.84 & 2.59 & 4.13 & 0.57 \\
\hline Absent & Cost, $¥$ & $2,612,704$ & 5,931 & 4,825 & 6,866 & Ref \\
\hline Present & & 124,647 & 8,185 & 5,714 & 8,986 & 2,120 \\
\hline \multicolumn{7}{|c|}{ No. of comorbidities } \\
\hline \multirow[t]{2}{*}{0} & No. of medications & 488,070 & 1.44 & 1.10 & 1.71 & Ref \\
\hline & Cost, $¥$ & 421,666 & 2,889 & 2,698 & 2,358 & Ref \\
\hline \multirow[t]{2}{*}{1} & No. of medications & 556,656 & 2.56 & 1.54 & 3.04 & 1.33 \\
\hline & Cost, $¥$ & 530,638 & 4,132 & 3,346 & 3,564 & 1,205 \\
\hline \multirow[t]{2}{*}{2} & No. of medications & 623,184 & 3.58 & 1.86 & 4.24 & 2.53 \\
\hline & Cost, $¥$ & 609,140 & 5,561 & 4,055 & 5,384 & 3,026 \\
\hline \multirow[t]{2}{*}{3} & No. of medications & 665,476 & 4.75 & 2.18 & 5.61 & 3.89 \\
\hline & Cost, $¥$ & 658,609 & 7,526 & 5,025 & 8,136 & 5,777 \\
\hline \multirow[t]{2}{*}{4} & No. of medications & 380,887 & 5.37 & 2.24 & 6.30 & 4.59 \\
\hline & Cost, $¥$ & 378,936 & 8,861 & 5,540 & 12,293 & 9,935 \\
\hline \multirow[t]{2}{*}{5} & No. of medications & 120,907 & 5.85 & 2.34 & 6.80 & 5.09 \\
\hline & Cost, $¥$ & 120,551 & 9,990 & 6,002 & 18,575 & 16,216 \\
\hline \multirow[t]{2}{*}{6} & No. of medications & 17,856 & 6.30 & 2.49 & 7.24 & 5.53 \\
\hline & Cost, $¥$ & 17,811 & 11,143 & 6,689 & 28,066 & 25,708 \\
\hline \multicolumn{7}{|c|}{ No. of complications } \\
\hline \multirow[t]{2}{*}{0} & No. of medications & $2,283,312$ & 3.44 & 2.25 & 3.17 & Ref \\
\hline & Cost, $¥$ & $2,180,877$ & 5,659 & 4,653 & 6,576 & Ref \\
\hline \multirow[t]{2}{*}{1} & No. of medications & 447,025 & 4.22 & 2.45 & 3.48 & 0.32 \\
\hline & Cost, $¥$ & 434,647 & 7,096 & 5,311 & 7,877 & 1,302 \\
\hline \multirow[t]{2}{*}{2} & No. of medications & 104,086 & 5.07 & 2.51 & 3.96 & 0.79 \\
\hline & Cost, $¥$ & 103,240 & 8,720 & 5,780 & 9,436 & 2,861 \\
\hline \multirow[t]{2}{*}{3} & No. of medications & 17,298 & 5.73 & 2.51 & 4.24 & 1.07 \\
\hline & Cost, $¥$ & 17,273 & 10,069 & 6,143 & 11,304 & 4,728 \\
\hline
\end{tabular}

Ref $=$ reference.

Note: Adjusted variables include age, sex, hypertension, coronary heart disease, dyslipidemia, stroke, chronic lung disease, osteoporosis, diabetic peripheral neuropathy, diabetic nephropathy, diabetic neuropathy, comorbidity, complication and a variable for the sampling time frame $(2016,2017$, and 2018). Values of all regression coefficients above were significant at $P<.001$. 


\section{Table 3. Insulin Use Over 3-Year Period}

\begin{tabular}{|c|c|c|c|c|c|}
\hline Type of Insulin & Used & $2016(\%)$ & $2017(\%)$ & $2018(\%)$ & $\chi^{2}$ Value $^{a}$ \\
\hline \multirow[t]{2}{*}{ Fast-acting } & No & 91.8 & 89.2 & 87.1 & \\
\hline & Yes & 8.2 & 10.8 & 12.9 & $2,790.6$ \\
\hline \multirow[t]{2}{*}{ Short-acting } & No & 87.2 & 88.3 & 89.2 & \\
\hline & Yes & 12.8 & 11.7 & 10.8 & 480.1 \\
\hline \multirow[t]{2}{*}{ Intermediate-acting } & No & 84.7 & 86.0 & 87.2 & \\
\hline & Yes & 15.3 & 14.0 & 12.8 & 597.8 \\
\hline \multirow[t]{2}{*}{ Long-acting } & No & 79.2 & 74.8 & 70.0 & \\
\hline & Yes & 20.8 & 25.2 & 30.0 & $5,226.4$ \\
\hline \multirow[t]{2}{*}{ Premixed } & No & 39.5 & 43.3 & 48.0 & \\
\hline & Yes & 60.5 & 56.7 & 52.0 & $3,453.6$ \\
\hline
\end{tabular}

with type 2 diabetes were treated with polypharmacy. ${ }^{30}$ Our study revealed a slight reduction in the use of polypharmacy.

Postprandial hyperglycemia is the main cause of type 2 diabetes in China, and is the basis for the use of antiglycemic drug(s). Although metformin (biguanide class) is the preferred drug for monotherapy, $\alpha$-glucosidase inhibitors (such as acarbose) are still the preferred antiglycemic drugs for Chinese patients with diabetes. Our data show that $46 \%$ of patients with diabetes in 2018 were using $\alpha$-glucosidase inhibitors, whereas only $43 \%$ of patients were using metformin. This could be attributed to the substantial differences in patient, blood glucose, and dietary characteristics between Chinese and Western populations. The therapeutic effect of the same drug in Chinese and Western patients with diabetes may be different. The MARCH trial (Metformin and Acarbose in China as the initial antiglycemic treatment) in 2008 was the first largescale direct comparison of acarbose and metformin as initial drug used in newly diagnosed patients with type 2 diabetes in China. ${ }^{31}$ After 24 and 48 weeks of treatment with acarbose $(100 \mathrm{mg}$, 3 times a day) in newly diagnosed patients with type 2 diabetes, the levels of glycated hemoglobin in the acarbose and metformin groups were similar. The reductions in 2 -hour postprandial blood glucose, postprandial insulin, body weight, and triglyceride concentration, however, was better with acarbose than metformin. Therefore, the use of acarbose is more suitable for the treatment of postprandial hyperglycemia in Chinese patients. Our results showed that $\alpha$-glucosidase inhibitors, alone or in combination, are the most commonly used drugs in Chinese patients with diabetes.

In terms of insulin selection, Chinese patients with diabetes use premixed insulin more frequently than other forms. Although the proportion of premixed insulin use has gradually declined, it still accounted for $52 \%$ of all diabetic patients who used insulin in 2018. The use of premixed insulin among Chinese patients is relatively high primarily because of their dietary pattern. Protein is the main dietary component for the Western population with more abundant breakfast and

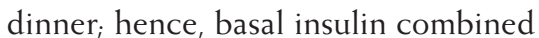
with oral drugs is more commonly used. For the Chinese population, the diet mainly consists of carbohydrates with more abundant lunch and dinner, resulting in increased postprandial blood glucose levels. Hence, premixed insulin is more suitable for Chinese people. Premixed insulin can improve both basal and bolus insulin secretion deficiency, and better simulate physiologic insulin secretion, which effectively controls fasting and postprandial blood glucose levels. ${ }^{32}$

A number of countries, realizing the high financial burden and potential poor health outcomes of patients with diabetes, have introduced financing and reimbursement policies to address these negative outcomes. ${ }^{33}$ Since the establishment of basic medical insurance followed by the new rural cooperative medical system, China has been able to effectively meet demands for medical treatments of all types. Further, Beijing has implemented a zero-plus policy on drug costs since April 2017, resulting in a 17\% decrease of $¥ 1,167$ (\$180) in total drug costs for diabetic patients in 2017 compared with 2016, a substantial reduction in financial the burden for patients with diabetes. At the same time, with the advent of newer and more efficient drug formulations and types of drugs, the number of drugs used has gradually decreased over the years.

Dipeptide peptidase- 4 inhibitors are a new class of antiglycemic drugs included in the 2017 medical insurance catalog, and subsequently, sodium-glucose transport protein-2 inhibitors were also approved in China. Glucagon-like peptide-1 analogs and various insulin products were also listed in succession. These new drugs and other factors are restructuring the antiglycemic drug market in China.

Our data suggest that the use of traditional Chinese medicines in Chinese patients with diabetes is gradually decreasing. Kaiyu Qingre Jiangzhuo formula was the first evidence-based traditional Chinese medicine used for blood glucose control in China. It has the same effect on blood glucose control as metformin, and no obvious side effects were reported. Although traditional Chinese medicines have a long history as 


\section{Figure 1. Changes in use of non-antiglycemic drugs (A) and changes in use of antiglycemic drugs (B).}

A. Changes in use of non-hypoglycemic drugs.

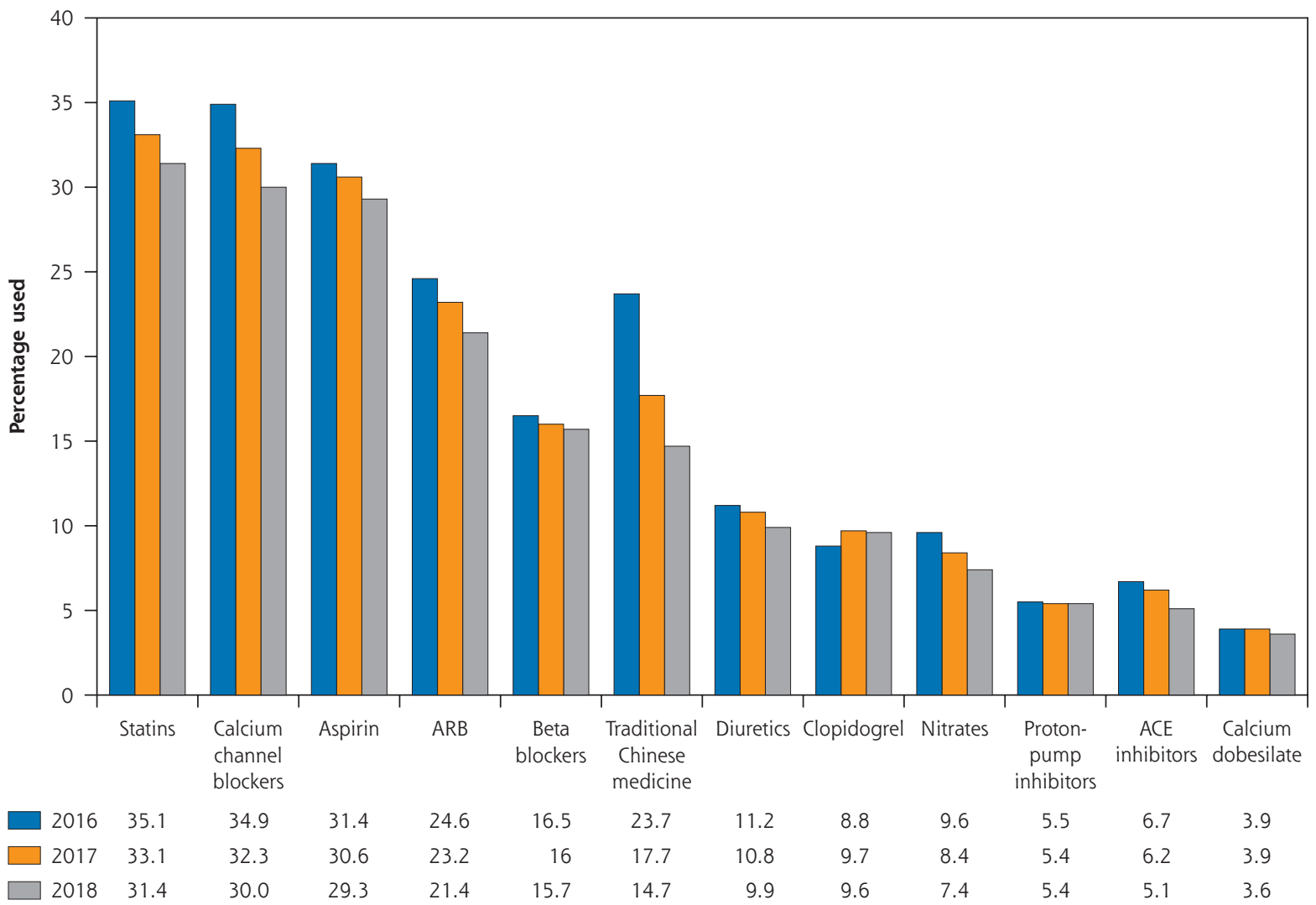

B. Changes in use of hypoglycemic drugs.

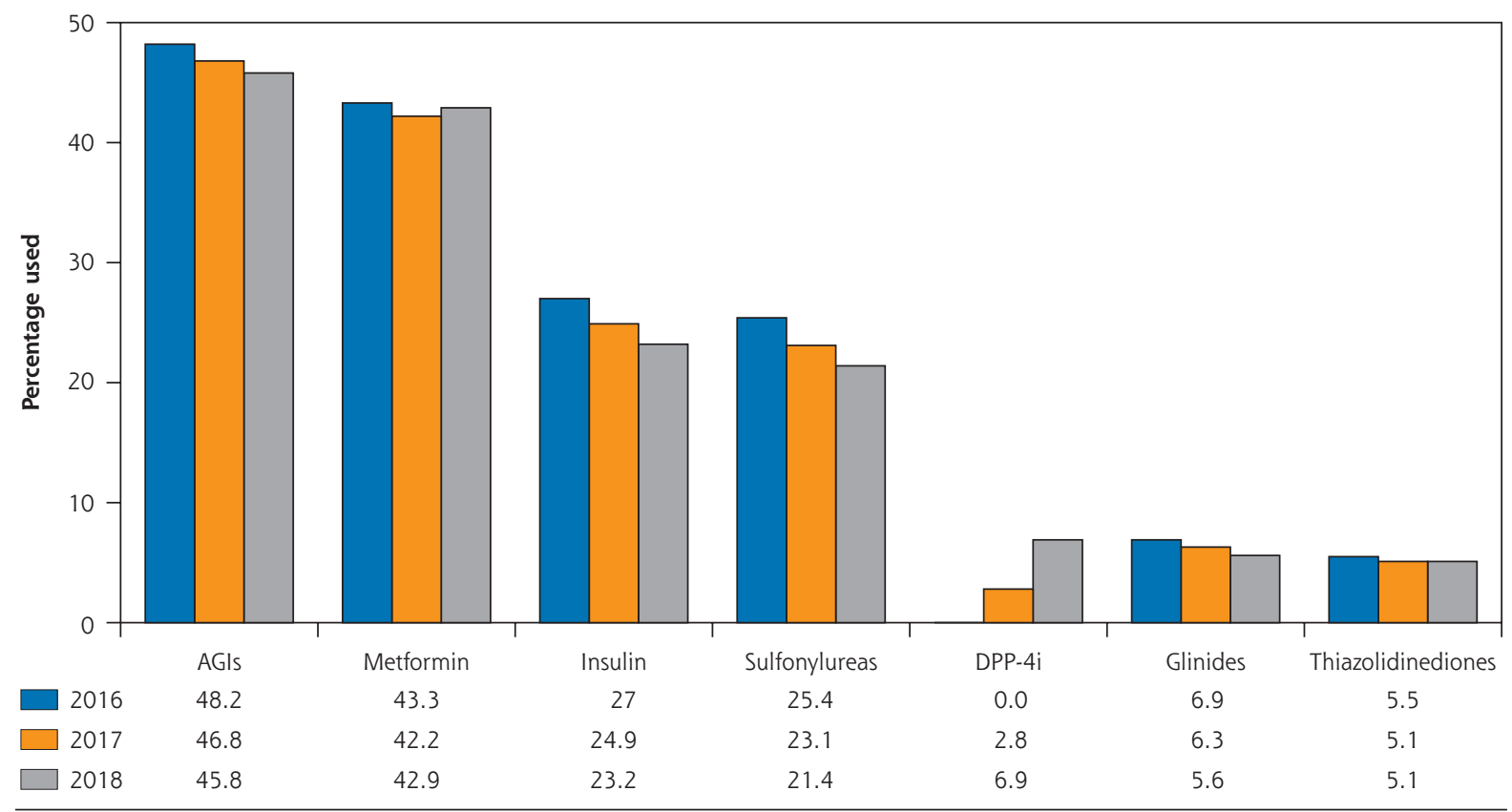

$\mathrm{AGI}=\alpha$-glucosidase inhibitor; $\mathrm{ACE}=$ angiotensin converting enzyme; $\mathrm{ARB}=$ angiotensin receptor blocker; DPP- $4 \mathrm{i}=$ dipeptidyl peptidase-4 inhibitor 
treatments for diabetes, ${ }^{34}$ randomized controlled trials are still lacking. At the same time, the side effects of traditional Chinese medicines are also a focus of clinical drug use. ${ }^{35}$ Presently, the research on Chinese medicine compound preparation is less popular, and the research on antiglycemic mechanism is relatively superficial. In addition, the clinical evaluation criteria for traditional Chinese medicines, drug interactions, and adverse reactions need to be further studied.

Our study is not without limitations. The study design is retrospective in nature, which introduces potential biases in data collection. Also the price for some medications may have changed over the study period. The study was drawn from all available persons enrolled in Beijing Medical Insurance over a 3-year period, but does not include those residing in this urban area who are not receiving prescription medications for diabetes. Also, due to the particularity of the medical insurance database, we cannot distinguish the specific types of medical insurance of individual patients. We used the general insurance with the largest number of people enrolled. The main strength of the study is its large sample size, and to the best of our knowledge, this is the first study from China to report the temporal changes over a 3 -year period of the prescription and direct medical costs of diabetes.

\section{CONCLUSION}

The complexity and costs of drug regimens prescribed to Chinese patients with diabetes are gradually decreasing. This dual decrease is partly attributable to use of antiglycemic drugs and non-antiglycemic drugs. This has been driven by the rational use of drugs, both old and new, in order to meet glycemic and cardiovascular risk targets established in newer guidelines. The decreased costs may be partly due to decreased prices of some commonly used drugs. China's health insurance policy appears to have achieved a remarkable success with cost savings serving to decrease the financial burden of medical care. Therapeutic drugs should be selected with caution based on the diet and lifestyle of Chinese people. This is the first large-scale treatment and cost analysis of diabetes since the implementation of medical insurance in China, and it is hoped that there may be lessons from this experience for other health systems in the world.

To read or post commentaries in response to this article, go to https://www.AnnFamMed.org/content/19/4/332/tab-e-letters.

Key words: diabetes mellitus; drug costs; drug therapy; medicare

Submitted August 8, 2020; submitted, revised, December 24, 2020; accepted January 5, 2021.

Funding support: This study was funded by National Natural Science Foundation of China (Grant No. 81670763 and 81471050).
- Supplemental materials: Available at https://www.AnnFamMed. org/content/19/4/332/suppl/DC1/.

\section{References}

1. World Health Organization. Global Report on Diabetes. World Health Organization; 2016.

2. International Diabetes Federation. The IDF Diabetes Atlas, 8th Edition. International Diabetes Federation; 2017.

3. Li X, Xu Z, Ji L, et al; Cooperative group on Direct Medical Cost Investigation of Diabetes in Chinese Urban Tertiary Hospitals, Chinese Diabetes Society. Direct medical costs for patients with type 2 diabetes in 16 tertiary hospitals in urban China: a multicenter prospective cohort study. J Diabetes Investig. 2019;10(2):539-551.

4. Hu C, Jia W. Diabetes in China: epidemiology and genetic risk factors and their clinical utility in personalized medication. Diabetes. 2018;67(1):3-11.

5. Wang L, Gao P, Zhang M, et al. Prevalence and ethnic pattern of diabetes and prediabetes in China in 2013. JAMA. 2017;317(24): 2515-2523.

6. Xu L, Wang Y, Collins CD, Tang S. Urban health insurance reform and coverage in China using data from National Health Services Surveys in 1998 and 2003. BMC Health Serv Res. 2007;7:37.

7. Yang W, Zhao W, Xiao J, et al. Medical care and payment for diabetes in China: enormous threat and great opportunity. PLoS One. 2012;7(9):e39513.

8. Gu S, Shi L, Shao H, et al. Choice across 10 pharmacologic combination strategies for type 2 diabetes: a cost-effectiveness analysis. BMC Med. 2020;18(1):378.

9. Hou X, Wan X, Wu B. Cost-effectiveness of canagliflozin versus dapagliflozin added to metformin in patients with type 2 diabetes in China. Front Pharmacol. 2019;10:480.

10. Shao H, Zhai S, Zou D, et al. Cost-effectiveness analysis of dapagliflozin versus glimepiride as monotherapy in a Chinese population with type 2 diabetes mellitus. Curr Med Res Opin. 2017;33(2): 359-369.

11. Hu H, Sawhney M, Shi L, et al. A systematic review of the direct economic burden of type 2 diabetes in china. Diabetes Ther. 2015; 6(1):7-16.

12. Williams $R$, et al. Global and regional estimates and projections of diabetes-related health expenditure: results from the International Diabetes Federation Diabetes Atlas, 9th edition. Diabetes Res. Clin. Pract. 162, (2020).

13. Yip WCM, Hsiao WC, Chen W, Hu S, Ma J, Maynard A. Early appraisal of China's huge and complex health-care reforms. Lancet. 2012;379(9818):833-842.

14. Ruan $Y$, Yan $Q H, X u J Y$, et al. Epidemiology of diabetes in adults aged 35 and older from Shanghai, China. Biomed Environ Sci. 2016; 29(6):408-416.

15. Lipska KJ, Krumholz H, Soones T, Lee SJ. Polypharmacy in the aging patient: a review of glycemic control in Older Adults With Type 2 Diabetes. JAMA. 2016;315(10):1034-1045.

16. Fezer Z, Kovacs L. The economic impact of diabetes. In: Proceedings from the IEEE 15th International Symposium on Intelligent Systems and Informatics; September 14-16, 2017; Subotica, Serbia. Abstract 21: 77-82.

17. Dall T, et al; American Diabetes Association. Economic costs of diabetes in the U.S. In 2007. Diabetes Care. 2008;31(3):596-615.

18. Rathmann W, Haastert B, Icks A, Giani G. Trends in outpatient prescription drug costs in diabetic patients in Germany, 1994-2004. Diabetes Care. 2007;30(4):848-853.

19. Wang W, Fu C, Zhuo H, Luo J, Xu B. Factors affecting costs and utilization of type 2 diabetes healthcare: a cross-sectional survey among 15 hospitals in urban China. BMC Health Serv Res. 2010;10:244. 
20. Kim TH, Chun KH, Kim HJ, et al. Direct medical costs for patients with type 2 diabetes and related complications: a prospective cohort study based on the Korean National Diabetes Program. J Korean Med Sci. 2012;27(8):876-882.

21. Li R, Bilik D, Brown MB, et al. Medical costs associated with type 2 diabetes complications and comorbidities. Am J Manag Care. 2013; 19(5):421-430.

22. Henriksson F, Agardh CD, Berne C, et al. Direct medical costs for patients with type 2 diabetes in Sweden. J Intern Med. 2000;248(5): 387-396.

23. Mata-Cases M, Casajuana M, Franch-Nadal J, et al. Direct medical costs attributable to type 2 diabetes mellitus: a population-based study in Catalonia, Spain. Eur J Health Econ. 2016;17(8):1001-1010.

24. Al-Maskari F, El-Sadig M, Nagelkerke N. Assessment of the direct medical costs of diabetes mellitus and its complications in the United Arab Emirates. BMC Public Health. 2010;10:679.

25. Shetty S, Secnik K, Oglesby AK. Relationship of glycemic control to total diabetes-related costs for managed care health plan members with type 2 diabetes. J Manag Care Pharm. 2005;11(7):559-564.

26. Domeikiené A, Vaivadaité J, Ivanauskiené R, Padaiga Ž. Direct cost of patients with type 2 diabetes mellitus healthcare and its complications in Lithuania. Medicina (Kaunas). 2014;50(1):54-60.

27. Bao X, Yang C, Fang K, Shi M, Yu G, Hu Y. Hospitalization costs and complications in hospitalized patients with type 2 diabetes mellitus in Beijing, China. J Diabetes. 2017;9(4):405-411.
28. Alva ML, Gray A, Mihaylova B, Leal J, Holman RR. The impact of diabetes-related complications on healthcare costs: new results from the UKPDS (UKPDS 84). Diabet Med. 2015;32(4):459-466.

29. Ji LN, Lu JM, Guo XH, et al. Glycemic control among patients in China with type 2 diabetes mellitus receiving oral drugs or injectables. BMC Public Health. 2013;13:602.

30. Li J, Chattopadhyay K, Xu M, et al. Prevalence and predictors of polypharmacy prescription among type 2 diabetes patients at a tertiary care department in Ningbo, China: a retrospective database study. PLoS One. 2019;14(7):e0220047.

31. Yang W, Liu J, Shan Z, et al. Acarbose compared with metformin as initial therapy in patients with newly diagnosed type 2 diabetes: an open-label, non-inferiority randomised trial. Lancet Diabetes Endocrinol. 2014;2(1):46-55.

32. Qian L, Xu L, Wang $X$, et al. Early insulin secretion failure leads to diabetes in Chinese subjects with impaired glucose regulation. Diabetes Metab Res Rev. 2009;25(2):144-149.

33. Mao W, Yip CW, Chen W. Complications of diabetes in China: health system and economic implications. BMC Public Health. 2019;19(1): 269.

34. Xie, W., Zhao, Y. \& Zhang, Y. Traditional Chinese medicines in treatment of patients with type 2 diabetes mellitus. Evid Based Complement Alternat Med. 2011: 726723.

35. Teschke R, Wolff A, Frenzel C, Eickhoff A, Schulze J. Herbal traditional Chinese medicine and its evidence base in gastrointestinal disorders. World J Gastroenterol. 2015;21(15):4466-4490.

\section{CHANGE-OF-ADDRESS FORM \\ FAMILY MEDICINE}

Please complete this form and mail to the following address or fax to Annals Circulation at 913-906-6080:

Annals of Family Medicine, Circulation Department, 11400 Tomahawk Creek Pkwy, Leawood, KS 66211-2680

Check if member of sponsoring organization:

$\begin{array}{ll}\square \text { AAFP } & \square \text { ABFM } \square \text { STFM } \square \text { ADFM } \\ \square \text { AFMRD } \square \text { NAPCRG } \square \text { CFPC }\end{array}$

ID number from label on your journal cover

OLD Information (Please print.)

NEW Information (Please print.)

\begin{tabular}{ll}
\hline Name \\
\hline Company (if applicable) \\
\hline Address (Street plus Apt or Ste) \\
\hline City & Postal Code (9-digit ZIP for US) \\
\hline Country & Fax \\
\hline Telephone & \\
\hline E-Mail & \\
\hline
\end{tabular}

Name

Company (if applicable)

Address (Street plus Apt or Ste)

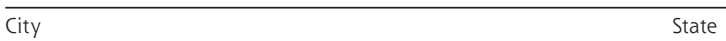

\begin{tabular}{ll}
\hline Country & Postal Code (9-digit ZIP for US)
\end{tabular}

Telephone

Fax 